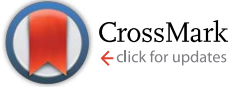

Cite this: RSC Adv., 2017, 7, 14069
Received 26th December 2016 Accepted 10th February 2017

DOI: 10.1039/c6ra28694a

rsc.li/rsc-advances

\section{Characterization of the biosorption properties of dormant spores of Aspergillus niger: a potential breakthrough agent for removing $\mathrm{Cu}^{2+}$ from contaminated water}

\begin{abstract}
Jing-Yao Wang and Chong-Wei Cui*
Recent work has focused on a new cultivation method (solid fermentation), by which a new form of Aspergillus niger was produced; the spores were characterised by a $2 \mu \mathrm{m}$ diameter and higher biosorption capacity than that of Aspergillus niger mycelium, which was prepared using the traditional method (submerged fermentation). The results showed that the maximum biosorption capacity for $\mathrm{Cu}^{2+}$ of the Aspergillus niger spore was $25.3 \mathrm{mg} \mathrm{g}^{-1}$ and that of the Aspergillus niger mycelium was only $10.1 \mathrm{mg} \mathrm{g}^{-1}$ at a natural $\mathrm{pH}$ with an initial concentration of $30 \mathrm{mg} \mathrm{L}^{-1}$. Meanwhile, the mechanism of the spores involved ion exchange $(\mathrm{P}, \mathrm{K}, \mathrm{Ca}$ and $\mathrm{Mg}$ ), complexation $(\mathrm{C}-\mathrm{O}, \mathrm{C}=\mathrm{O}, \mathrm{C}-\mathrm{N}$ and $\mathrm{C}-\mathrm{H})$ and electrostatic attraction, and $\mathrm{Cu}-\mathrm{O}$ was formed during the process. Moreover, the spores exhibited a short biosorption equilibrium time of $60 \mathrm{~min}$ over a $\mathrm{pH}$ range of 4.0-6.0, and the data fitted well with the pseudo-second-order kinetic equation and the Freundlich isotherm. A thermodynamic study demonstrated that the process was spontaneous and endothermic. In addition, the amplification of Aspergillus niger spores on an agricultural waste medium was from $10^{6}$ to $10^{9}$.
\end{abstract}

\section{Introduction}

Biosorption is a recent effective method to remove heavy metals from wastewater and the biosorbents are usually divided into three types: microbiological, agricultural waste and algae. Moreover, those that are microbiological include bacteria, fungi and actinomycetes. In addition, fungal biosorbents (yeast, filamentous fungi and macrofungi) can biosorb metal ions more effectively as the compositions of their cell walls (mannan, glucan, chitin, cellulose and protein) possess strong negative charges. $^{1}$

Previously, filamentous fungi were used widely in heavy metal wastewater treatment as they can be removed from a liquid medium easily, and Aspergillus niger biosorbents, as one kind of mycelium fungus, were commonly used because they are inexpensive and non-toxic, and they are negatively charged on the fungus surface which leads to their cationic combining ability. ${ }^{2-4}$ So, in the past, researchers always prepared biosorbents from mycelium. However, this kind of biosorbent has two drawbacks: (1) the process for preparing the biosorbents was a costly and usually lengthy procedure consisting of shaked cultivation of the liquid medium, filtration, drying in an oven, crushing, and lastly, passing through a sieve to create the

School of Municipal and Environmental Engineering, Harbin Institute of Technology, Harbin 150090, China. E-mail: 18845181188@126.com; Tel: +8618845181188 biosorbent powder; (2) the biosorption capacity was usually found to be low. ${ }^{5-7}$

Aspergillus niger spores are a kind of reproductive propagule produced in the later stage of Aspergillus niger growth. In contrast with mycelium biosorbents acquired from a liquid medium, spores can only be achieved from a solid medium. In addition, they have small diameters and their surfaces are rough. ${ }^{8}$ The surfaces of them are typically characterized by negative zeta potentials over a wide range of $\mathrm{pH}$ values. ${ }^{9}$ Spores are able to survive in extreme conditions, resisting chemical and physical attack. ${ }^{10}$ In addition, spores can grow on most agricultural waste without added nutrition. ${ }^{11}$ These characteristics may lead to the feasibility of their use in heavy metal biosorption.

To the best of our knowledge, there are no reports with regard to the application of spores of Aspergillus niger to remove copper. On the basis of the available literature, it is hypothesized that Aspergillus niger spores may be a promising candidate for such biosorption studies, thanks to their high biosorption capacity and being easy to acquire. In addition, copper is used as a probe to test the spores' effectiveness.

The aim of this study was to explore the characteristics and mechanisms of spore biosorption in order to gain a deeper insight into the potential of Aspergillus niger spores as a biosorbent. For this purpose, the spores launched by aerial mycelium in solid media were obtained directly, and the effect of spore dosage, $\mathrm{pH}$ level, contact time and initial metal concentration on the biosorption process was investigated using 
a batch biosorption procedure. Finally, the spores before and after heavy metal ion biosorption were characterized using SEM-EDX, FTIR, XPS and FETEM.

\section{Materials and methods}

\subsection{Microbiology and medium}

Aspergillus niger CMCC98003 was purchased from CMCC (B).

The liquid Martin medium (for submerged fermentation) was composed of peptone $(5 \mathrm{~g})$, yeast powder $(1 \mathrm{~g})$, glucose (20 $\mathrm{g}), \mathrm{KH}_{2} \mathrm{PO}_{4}(1 \mathrm{~g}), \mathrm{MgSO}_{4}(0.5 \mathrm{~g})$, and $1 \mathrm{~L}$ of deionized water with a $\mathrm{pH}$ of 6.4 .

The solid medium was the liquid Martin medium with $15 \%$ agar.

The agricultural waste medium was agricultural waste crushed into a powder with a diameter of about $0.3 \mathrm{~mm}$.

\subsection{Preparation and collection of biosorbent spores and mycelium}

2.2.1 Spores. Aspergillus niger CMCC98003 was smeared on solid medium dishes. When abundant spores were generated, the bottoms of the dishes were tapped and the spores which fell out were collected, then kept at room temperature until required for further studies.

2.2.2 Mycelium. The liquid martin medium with inoculated Aspergillus niger CMCC98003 was shaken on a rotary shaker at $150 \mathrm{rpm}$ at $30{ }^{\circ} \mathrm{C}$. After 5 days, mycelium pellets were obtained, which were filtered using $0.45 \mu \mathrm{m}$ pore size paper. The mycelium pellets were deactivated by heating in a shaker flask in an autoclave at $121{ }^{\circ} \mathrm{C}$ for $15 \mathrm{~min}$. They were then washed with deionized water. After washing, the collected mycelium pellets were dried at $50{ }^{\circ} \mathrm{C}$ in an electrically heated blast dry box to a constant weight. The dried mycelium pellets were crushed with a grinder, and sieved with a standard sieve $(0.3 \mathrm{~mm})$ to obtain the dried mycelium powder.

\subsection{Fermentation substrate experiment}

Rice straw, corn stalk, rice husk and wood flour were washed with distilled water, crushed with a grinder (FW100, Tianjin Theis brand) and sieved with a standard sieve to obtain a powder with a particle diameter of $0.3 \mathrm{~mm}$. Then, the powders were dried in an electrically heated blast dry box to a constant weight. The spore suspension and powder were mixed at a ratio of $1: 1$. Three days later, when the aerial mycelia of Aspergillus niger covered the whole medium, the number of spores were counted using a blood cell counting chamber.

\subsection{Biosorption experiment}

2.4.1 The effect of factors (spore dosage, $\mathrm{pH}$, contact time and initial concentration) on $\mathrm{Cu}^{2+}$ biosorption. The effects of the biosorbent dosage $(0.05,0.1,0.15,0.2$ and $0.25 \mathrm{~g}), \mathrm{pH}(1.0$, 2.0, 3.0, 4.0, 5.0 and 5.3), contact time $(3,5,10,15,30,45,60,90$, and $120 \mathrm{~min})$ and initial metal ion concentration (10, 20, 30, 50, $100,150,200$, and $250 \mathrm{mg} \mathrm{L}^{-1}$ ) on the biosorption capacity were studied. Meanwhile, as a control, the Aspergillus niger mycelium in different dosages, representing the traditional preparation method, was analyzed. All the samples were shaken at $30^{\circ} \mathrm{C}$ and $100 \mathrm{rpm}$ for two hours. The reason that we chose the $\mathrm{pH}$ range was that, according to the calculation from the solubility product, the $\mathrm{pH}$ of precipitate appearance of $\mathrm{Cu}^{2+}$ was 5.84 , and the $\mathrm{pH}$ of $30 \mathrm{mg} \mathrm{L}^{-1} \mathrm{CuSO}_{4}$ was 5.3 , so the range of detected $\mathrm{pH}$ was set from 1 to 5 and 5.3 (natural $\mathrm{pH}$ ).

2.4.2 Desorption experiment. For the desorption experiments, firstly, $50 \mathrm{mg}$ of spores was added to a flask containing $100 \mathrm{~mL}$ of $30 \mathrm{mg} \mathrm{L}^{-1} \mathrm{Cu}^{2+}$ solution. After attaining equilibrium, the exhausted biosorbent was separated from the solution using a centrifuge. Subsequently, metal ions were eluted using $0.1 \mathrm{M}$ $\mathrm{HCl}$, then the mixture was filtered and the residue was washed repeatedly with deionized water in order to remove excess acid. After washing, the regenerated adsorbent was dried at $50{ }^{\circ} \mathrm{C}$ for $4 \mathrm{~h}$ and further used for the next adsorption process with the same adsorbent dosage of $50 \mathrm{mg}$. In this way, consecutive adsorption-desorption cycles were repeated five times using the same biosorbent. ${ }^{\mathbf{1 2}}$

2.4.3 Biosorption of other heavy metals and a binary metal solution. The biosorption of $\mathrm{Hg}^{2+}, \mathrm{Pb}^{2+}$ and $\mathrm{Cd}^{2+}$ by the spores was investigated in batch biosorption experiments, and then three pairs of competitive biosorption experiments for $\mathrm{Cu}^{2+}$ and $\mathrm{Hg}^{2+}, \mathrm{Cu}^{2+}$ and $\mathrm{Pb}^{2+}$, and $\mathrm{Cu}^{2+}$ and $\mathrm{Cd}^{2+}$ ions were performed using the spores. The initial concentration of all the heavy metals was $30 \mathrm{mg} \mathrm{L}^{-1}$, and the biosorbent dosage was $0.05 \mathrm{~g}$. The metals and biosorbent were shaken together at $30^{\circ} \mathrm{C}$ for $2 \mathrm{~h}$.

\subsection{Spore characterization}

Fourier Transform Infrared Spectroscopy (FTIR) was used to ascertain the presence of specific chemical groups in the dried biosorbents (mycelium pellets and aerial mycelia). ${ }^{13}$ The dried spores used for Scanning Electron Microscopy (SEM) analysis were mounted on metal stubs and coated with gold for better image contrast. An SU8010 scanning electron microscope from Japan was used to view the images. ${ }^{14}$ XPS was performed (PHI 5400 ESCA System) with $\mathrm{Al} \mathrm{K} \alpha$ radiation ( $h \nu=1486.6 \mathrm{eV}$ with an $\mathrm{eV}$ deviation of \pm 0.2 in the binding energy position) and the pass energies of the wide scan and narrow scan were 178.95 and $22.35 \mathrm{eV}$, respectively. In addition, a Talos F200x Field Emission Transmission Electron Microscope (FETEM) from America was used to view the spores.

2.5.1 Zeta potential analysis. The spores were treated in four different ways, giving: (1) fresh spores (acquired from dishes cultivated for four days); (2) dry spores (fresh biosorbent dried at room temperature to a constant weight); (3) mutant spores (exposed to $30 \mathrm{~W}$ UV for $1 \mathrm{~min}$ ); (4) inactive biosorbent (fresh biosorbent dried at $160{ }^{\circ} \mathrm{C}$ for two hours). These four kinds of sample were dispersed in deionized water and the charge on their surface was tested using a zeta potential meter (ZetaSizer 3000, Malvern corporation).

\section{Results and discussion}

\subsection{Growth situation of spores on different agricultural waste media}

Fig. 1 shows the growth curve of the spores on different agricultural waste media. The data of the fermentation substrate 


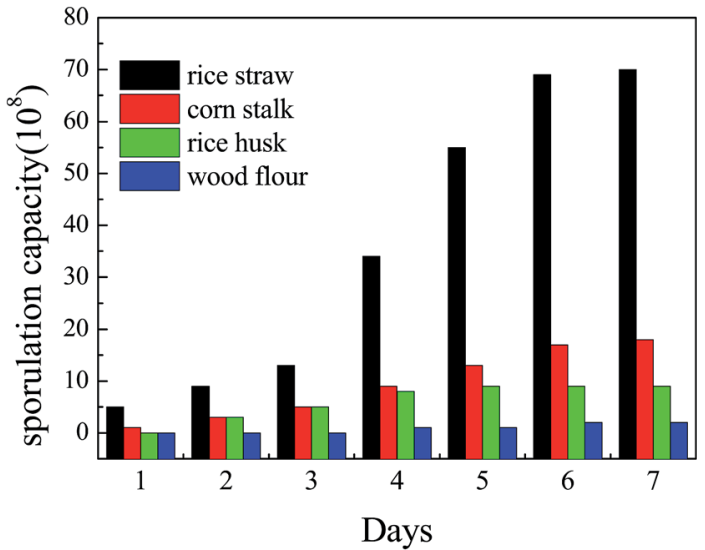

Fig. 1 The number of spores $\left(10^{8}\right)$ grown on agricultural and forestry residues.

experiments show that the spores can grow on many kinds of agricultural waste, such as rice straw, corn stalk and rice husk, and that wood flour can't provide nutrition for spore growth since it contains too much lignin. This phenomenon indicates that sporogony can happen greatly and quickly on a solid medium such as agricultural waste, which eliminates the time and effort needed to prepare the biosorbents, and as it is cheap and easy to acquire, it can be used directly without any desorption and reuse.
Moreover, most of these agricultural waste types were also made to be raw or modified biosorbents to biosorb heavy metal waste water, and have been very popular in recent research. ${ }^{\mathbf{1 5 , 1 6}}$ Therefore, growing spores on agricultural waste is an innovative method and the medium (agricultural and forestry residues) can also increase the biosorption capacity. ${ }^{\mathbf{1 7}}$

\subsection{Biosorption experiments}

3.2.1 The effect of factors (spore dosage, $\mathrm{pH}$, contact time and initial concentration) on $\mathrm{Cu}^{2+}$ biosorption. As Fig. 2a shows, the biosorption capacity of the spores was always higher than that of the mycelium; when the biosorbent dosage was $0.05 \mathrm{~g}$ and the initial concentration was $30 \mathrm{mg} \mathrm{L}^{-1}$, the maximum biosorption value of the spore biosorbent for $\mathrm{Cu}^{2+}$ was $25.3 \mathrm{mg} \mathrm{g}^{-1}$, and the mycelium value was only $10.1 \mathrm{mg} \mathrm{g}^{-1}$. In addition, Table 1 shows some gathered data about the biosorption capacity of pretreated or modified Aspergillus niger mycelium. In other words, the spores exhibited far better biosorption properties than traditional Aspergillus niger mycelium.

The tendency of spore biosorption implied that the spore biosorption reaction was able to adapt to a wide (3-5.3) range of pH levels (Fig. 2b). The best $\mathrm{pH}$ was similar to that which Idris Sargin found in his study, in which the biosorbents were Ustilago maydis immobilized chitosan microcapsules. ${ }^{20}$ It is reported that the dominant copper species in the solution of $\mathrm{pH}$ 3-5 were $\mathrm{Cu}^{2+}$ and $\mathrm{CuOH}^{+}$, while in a solution with a $\mathrm{pH}$ above 5.8 , the $\mathrm{Cu}^{2+}$ ions precipitate, making the biosorption of $\mathrm{Cu}^{2+}$
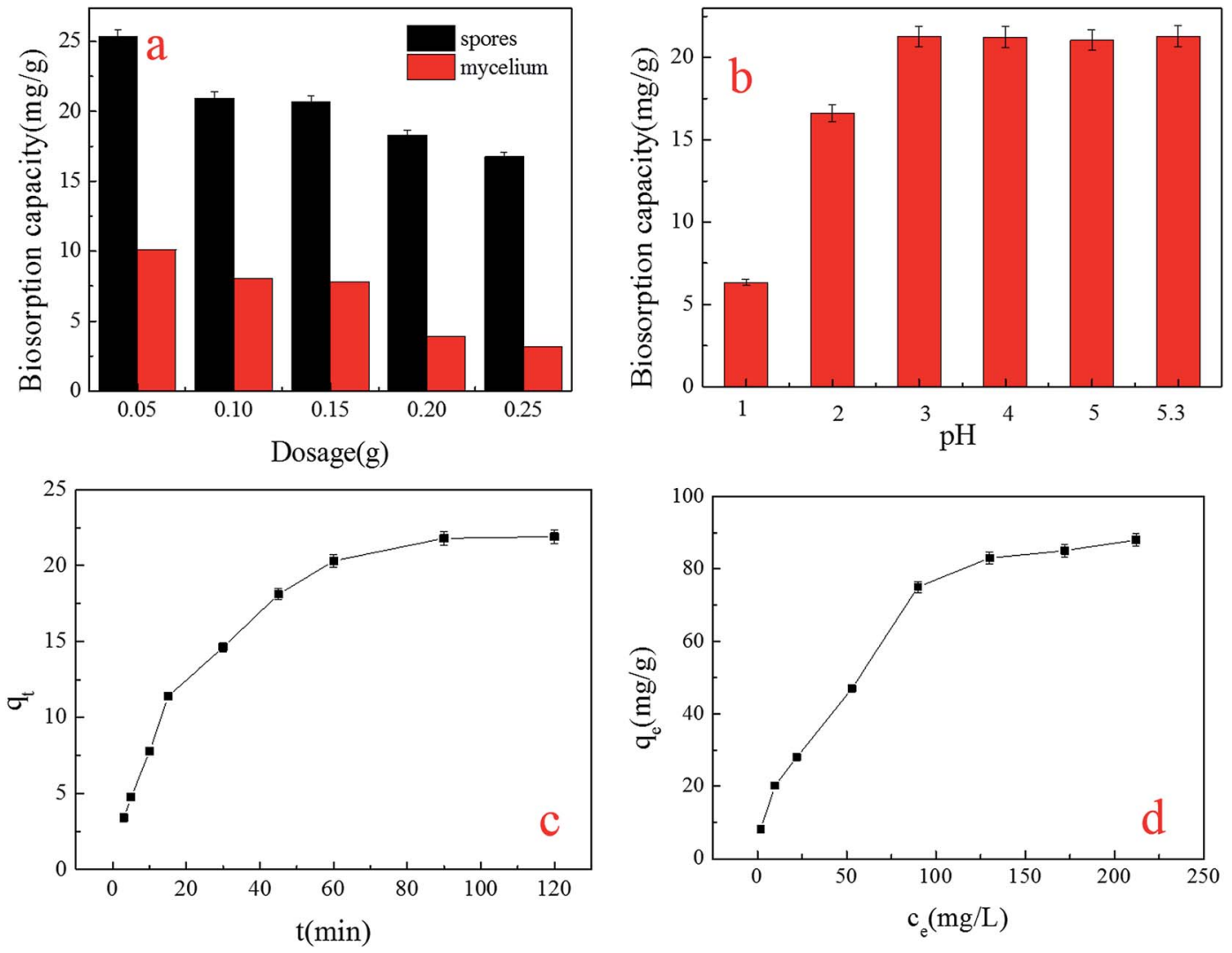

Fig. 2 Effect of factors on the biosorption capacity for $\mathrm{Cu}^{2+}$ by spores: (a) spore dosage; (b) pH level; (c) contact time; (d) initial concentration. 
Table 1 Comparison of the biosorption capacity for $\mathrm{Cu}^{2+}$ of spores and mycelium of Aspergillus niger under different conditions

\begin{tabular}{|c|c|c|c|c|c|}
\hline Biosorbent & $\begin{array}{l}\text { Initial concentration } \\
\left(\mathrm{mg} \mathrm{L}^{-1}\right)\end{array}$ & $\mathrm{pH}$ & Biomass dosage ( $\mathrm{g} \mathrm{L}^{-1}$ ) & $\begin{array}{l}\mathrm{Cu}^{2+} \text { uptake } \\
\left(\mathrm{mg} \mathrm{g}^{-1}\right)\end{array}$ & Reference \\
\hline Spores & 30 & 5.3 & 1 & 25.3 & This study \\
\hline PVA-immobilized mycelium & 30 & 5.5 & 1 & 8.9 & 6 \\
\hline Mycelium & 30 & 5.5 & 1 & 5.8 & 6 \\
\hline HCl-pretreated mycelium & 10 & 5 & - & 13.1 & 18 \\
\hline $\mathrm{NaOH}$-pretreated mycelium & 250 & 5 & 1 & 28.7 & 19 \\
\hline
\end{tabular}

Table 2 The capacity of biosorption and desorption of $\mathrm{Cu}^{2+}$ by spores for five cycles

\begin{tabular}{llll}
\hline Times & $\begin{array}{l}\text { Biosorption } \\
\left(\mathrm{mg} \mathrm{g}^{-1}\right)\end{array}$ & $\begin{array}{l}\text { Desorption } \\
\left(\mathrm{mg} \mathrm{g}^{-1}\right)\end{array}$ & $\begin{array}{l}\text { Recovery rate } \\
(\%)\end{array}$ \\
\hline 1 & & & \\
2 & 25.3 & 25.2 & 99.6 \\
3 & 25.1 & 24.9 & 99.2 \\
4 & 24.9 & 24.7 & 99.1 \\
5 & 24.6 & 24.3 & 98.8 \\
& 24.2 & 23.9 & 98.7
\end{tabular}

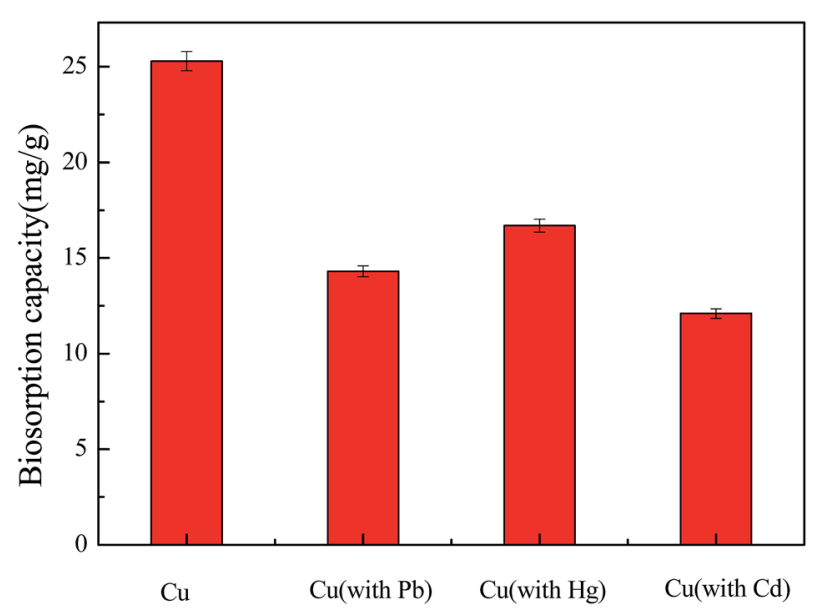

Fig. 3 Biosorption capacity for $\mathrm{Cu}^{2+}$ and binary metal ion mixtures with other kinds of heavy metal. ions impossible. ${ }^{21,22}$ In addition, the natural $\mathrm{pH}$ level of $30 \mathrm{mg}$ $\mathrm{L}^{-1} \mathrm{Cu}^{2+}$ was 5.3 , meaning that in the actual treatment of $\mathrm{Cu}^{2+}$ waste water, it is not necessary to adjust the $\mathrm{pH}^{23}$

From Fig. 2c, we can see that the biosorption yield of $\mathrm{Cu}^{2+}$ increased sharply in the first 30 minutes, and then increased steadily until the contact time reached 120 minutes. A further increase in contact time did not enhance the biosorption. This phenomenon may be due to the fact that, initially, all active sites on the surface of the adsorbents were vacant and the solution concentration was high. After that period, many surface active sites were occupied, so no increase in metal uptake was observed. For further experiments, therefore, the optimum contact time was determined to be 120 minutes.

Different initial concentrations of $\mathrm{Cu}^{2+}$ were investigated (Fig. 2d). The biosorption capacity of spores decreased with the increase in initial concentration until at last, a stable value was reached. This can be caused by the limitation of biosorption active sites; when the sites were occupied by $\mathrm{Cu}^{2+}$, no more $\mathrm{Cu}^{2+}$ could be biosorbed.

3.2.2 Desorption experiments. The effect of regeneration cycles of the spores on the biosorption capacity was tested 5 times and the results are shown in Table 2 . It is seen that the biosorption capacities of the spores for $\mathrm{Cu}^{2+}$ were almost not affected and the regeneration efficiency of the biosorbent was generally high, which can be attributed to the fact that the main content of the spores' cell wall is chitosan, and the spores have the ability to resist an external hostile environment. ${ }^{9}$ The results indicate that the spent spores could be effectively regenerated
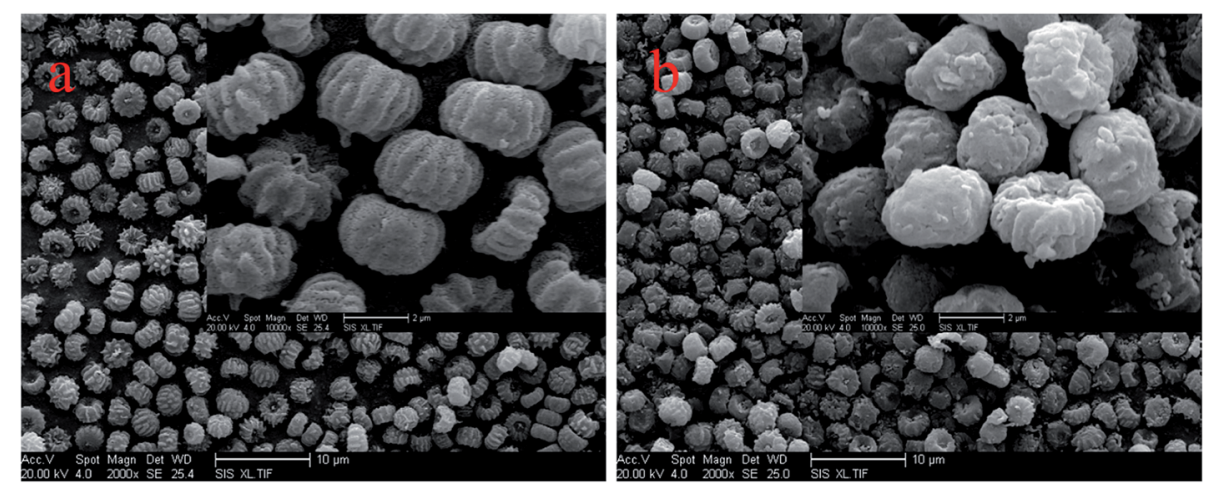

Fig. 4 SEM images of the spores before (a) and after (b) heavy metal biosorption. 

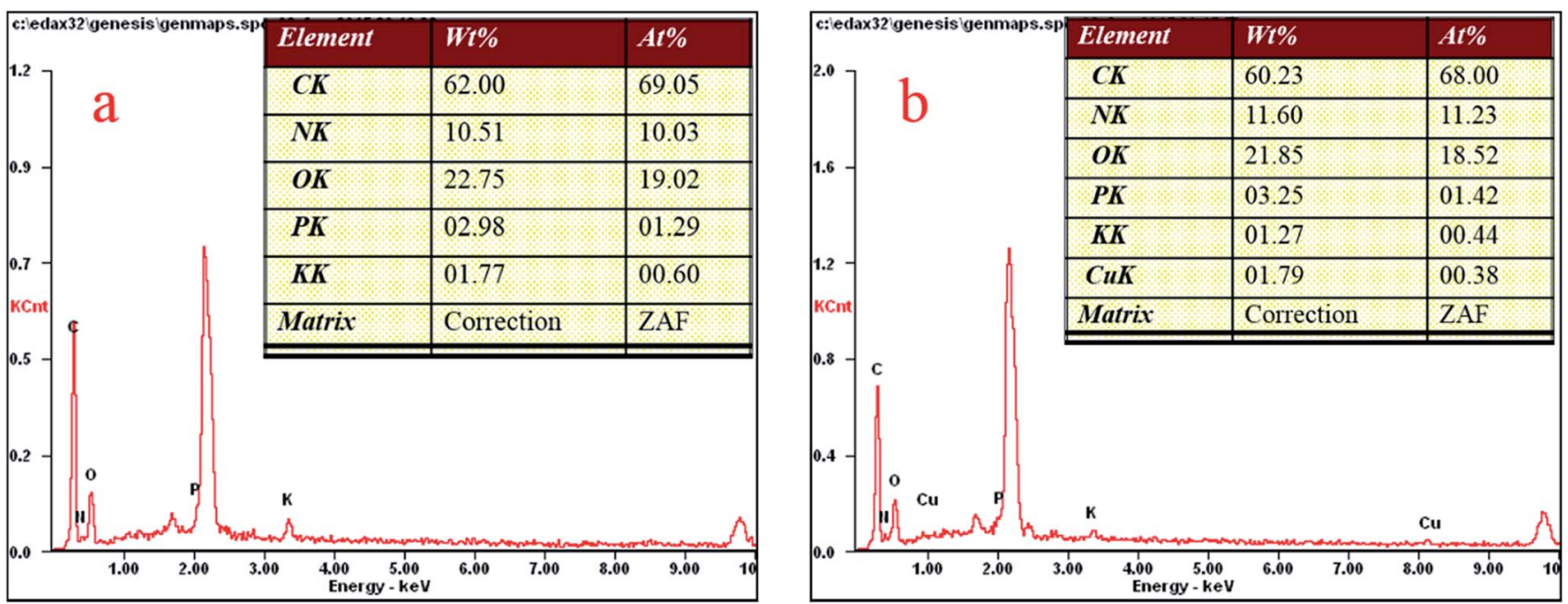

Fig. 5 EDX analysis of the spores before (a) and after (b) heavy metal biosorption.

using $\mathrm{HCl}$, and reused at least 5 times without decreasing their biosorption capacity significantly. However, in China, a great agricultural country, agricultural waste resources are extremely plentiful, so Aspergillus niger spores can have an excellent opportunity to grow and reproduce. Hence, it was very easy to acquire this kind of biosorbent. ${ }^{17}$

3.2.3 Biosorption of other heavy metals and binary metal solutions. In order to test the selectivity of the spores towards the removal of $\mathrm{Cu}^{2+}$, biosorption by the spores of other kinds of heavy metal such as $\mathrm{Pb}^{2+}, \mathrm{Hg}^{2+}$ and $\mathrm{Cd}^{2+}$ was investigated in a single ion solution. When the biosorbent dosage was $0.05 \mathrm{~g}$ and the initial concentration was $30 \mathrm{mg} \mathrm{L}^{-1}$, the maximum biosorption values of the spore biosorbents for $\mathrm{Pb}^{2+}, \mathrm{Hg}^{2+}$, and $\mathrm{Cd}^{2+}$ were 27.8, 29.04, and $24.34 \mathrm{mg} \mathrm{g}^{-1}$, respectively. However, when $\mathrm{Cu}^{2+}$ was added, the biosorption capacities for $\mathrm{Pb}^{2+}, \mathrm{Hg}^{2+}$, and $\mathrm{Cd}^{2+}$ decreased to $16.8,19.5$, and $11.02 \mathrm{mg} \mathrm{g}^{-1}$, respectively, and at the same time, the biosorption capacity for $\mathrm{Cu}^{2+}$ also decreased from $25.3 \mathrm{mg} \mathrm{g}^{-1}$

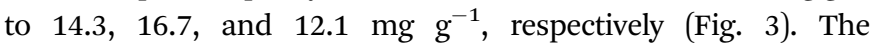
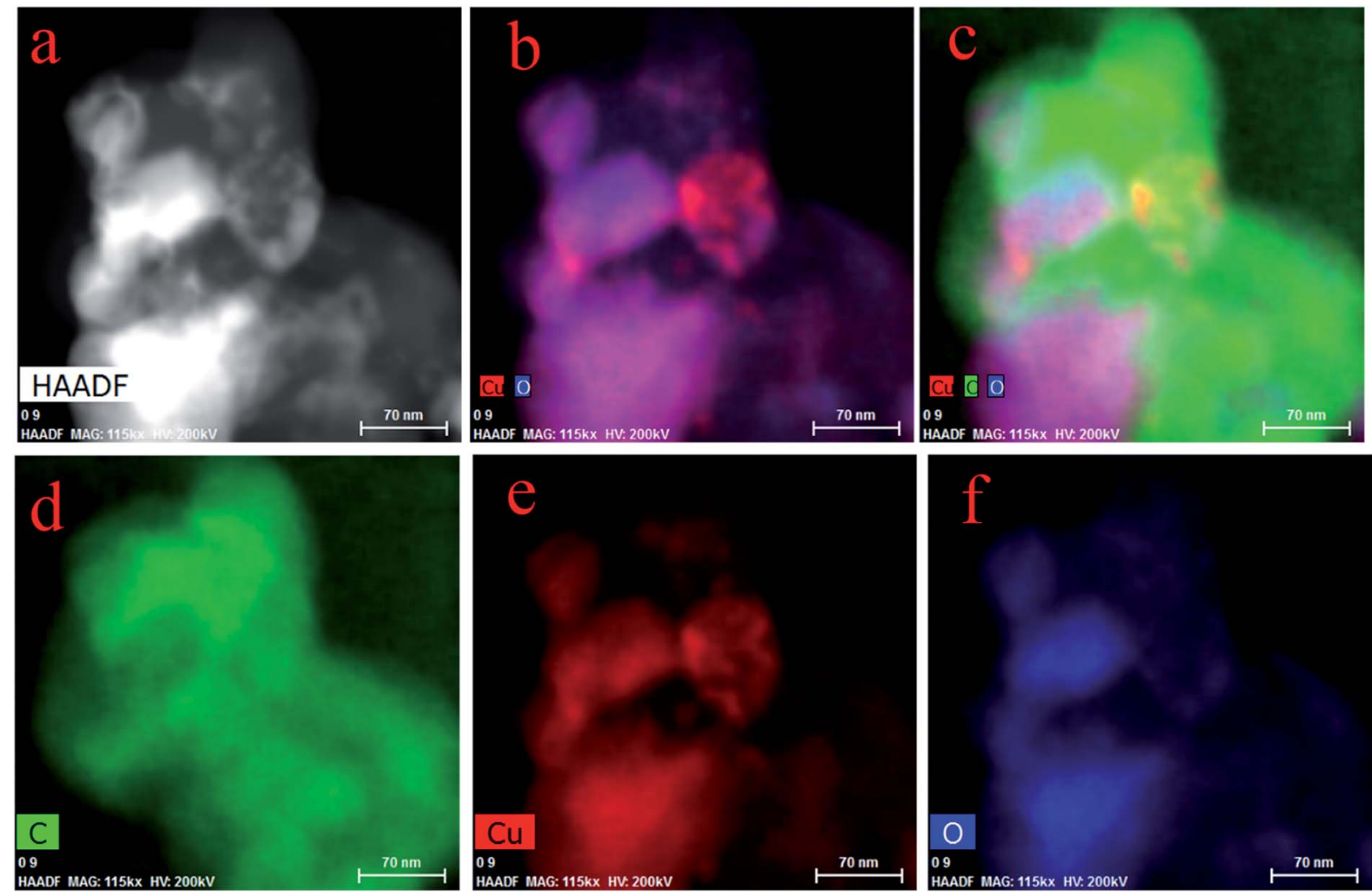

Fig. 6 FETEM images of metal deposits and elements. 

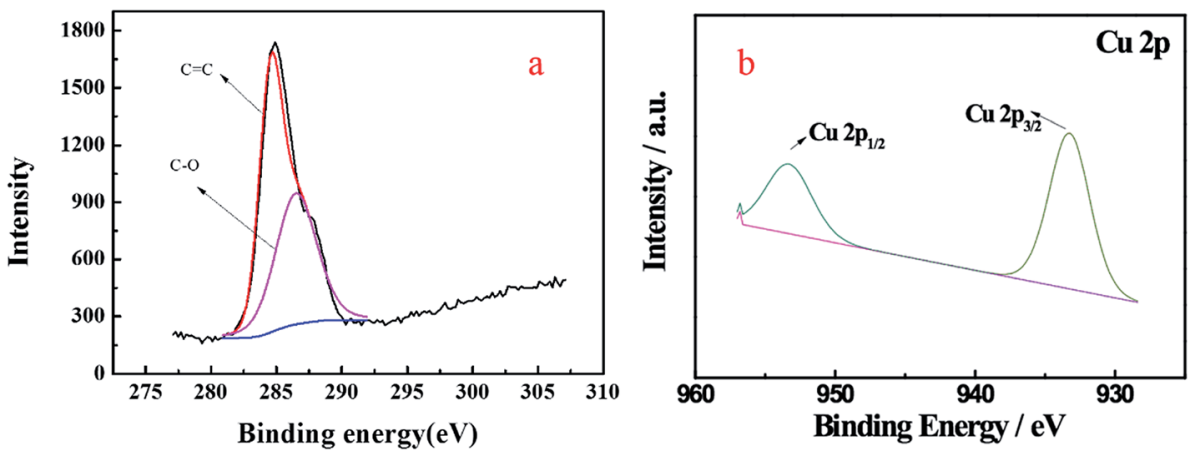

Fig. 7 XPS spectra of $\mathrm{Cu}$ after spore biosorption.

biosorption capacities of spores in the presence of the binary metal mixture were lower than those of the spores under noncompetitive conditions. The order of affinity under competitive conditions was as follows (based on $\mathrm{mg} \mathrm{g}^{-1}$ accumulation): $\mathrm{Hg}^{2+}>\mathrm{Pb}^{2+}>\mathrm{Cd}^{2+}$. This order was the same under noncompetitive conditions. This sequence was in accordance with Akar's study, ${ }^{2}$ and may be caused by the differences in atomic mass and atomic radius.

\subsection{Characteristics of spores before and after biosorption}

Fig. 4 shows the Aspergillus niger spores before (a) and after (b) copper biosorption. As can be seen, the spores have a small diameter of about $2 \mu \mathrm{m}$ and there are many small bumps and wrinkles on the surface of the spores, and the surface layer exhibits microcavities and porous structures, which seemed to be available for the biosorption process. After biosorption, the edges of the bumps were not as clear as before the biosorption.

According to the EDX results, shown in Fig. 5, the copper content (atomic percentage, or at\%) on the cell surfaces (at\% of 0 to 0.38 ) and the content of $\mathrm{P}$ (at\% of 1.29 to 1.42) increased as the $\mathrm{N}$ content increased (at\% of 10.03 to 11.23 ), while the $\mathrm{C}$ (at\% of 69.05 to 68 ), $\mathrm{O}$ (at\% of 19.02 to 18.52 ), and

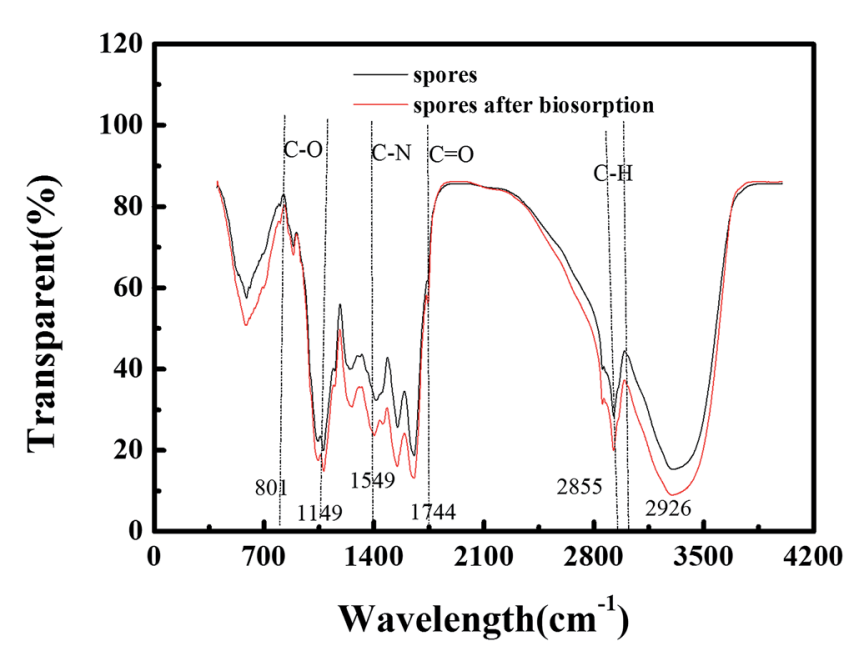

Fig. 8 FTIR spectra of spores before and after biosorption.
$\mathrm{K}$ (at\% of 0.6 to 0.44 ) content decreased after $\mathrm{Cu}^{2+}$ biosorption. Undoubtedly, this kind of relative content alteration of $\mathrm{N}, \mathrm{P}$, and $\mathrm{Cu}$ was related to the release of $\mathrm{C}, \mathrm{O}$, and $\mathrm{K}$ and the adsorption of $\mathrm{Cu}^{2+}$ to the cell surface during $\mathrm{Cu}^{2+}$ biosorption. $\mathrm{O}-, \mathrm{N}-$, and P-containing functional groups on the biomass possibly contributed to $\mathrm{Cu}^{2+}$ binding onto the biomass. ${ }^{24}$ In addition, we obtained a series of data for the liquid after $\mathrm{Cu}^{2+}$ biosorption, and the amounts of $\mathrm{Ca}^{2+}, \mathrm{K}^{+}$, $\mathrm{Mg}^{2+}$, and $\mathrm{Na}^{+}$were $0.67,13.20,2.77$, and $1.32 \mathrm{mg} \mathrm{g}^{-1}$, respectively. The results above infer that the process involved ion exchange. ${ }^{24,25}$

\subsection{FETEM of the spores after biosorption}

The mapping of FETEM can display the distribution and condition of elements. Fig. $6 a-c$ indicate the formation of metal deposits. In Fig. 6a, there are some light spots, which indicate the existence of $\mathrm{Cu}$, and Fig. $6 \mathrm{~b}$ and $\mathrm{c}$ show that $\mathrm{Cu}$ (red part) was combined with $\mathrm{O}$ (blue part), which led to the formation of $\mathrm{Cu}-\mathrm{O}$ (purple part). However, there is no evidence in Fig. $6 \mathrm{c}$ of a compound of $\mathrm{Cu}$ and C. Since carbonyl and carboxyl groups (containing $\mathrm{C}, \mathrm{H}$ and $\mathrm{O}$ ) were abundant on the spores, when the biosorption happened, organic groups were involved as a whole, but $\mathrm{Cu}$ combined with $\mathrm{O}$ only. Fig. $6 \mathrm{~d}-\mathrm{f}$ show the elements of $\mathrm{C}$, $\mathrm{Cu}$ and $\mathrm{O}$, respectively.

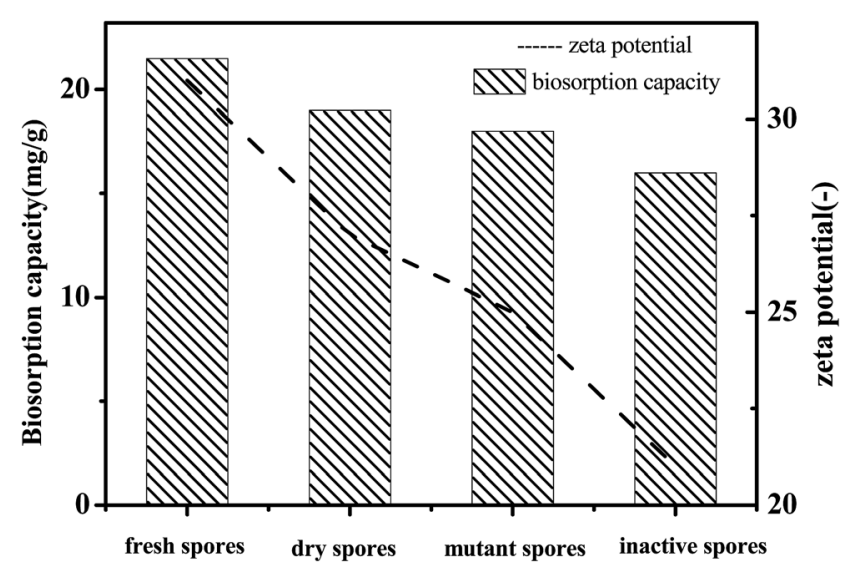

Fig. 9 Zeta potential and $\mathrm{Cu}^{2+}$ biosorption capacity of the differently treated spores. 
Table 4 Simulation of isotherm sorption models and corresponding parameters

\begin{tabular}{|c|c|c|c|c|c|c|c|c|c|}
\hline $\begin{array}{l}\text { Temperature } \\
\text { (K) }\end{array}$ & \multicolumn{3}{|l|}{ Langmuir } & \multicolumn{3}{|l|}{ Freundlich } & \multicolumn{3}{|c|}{ Temkin } \\
\hline 298 & 100 & 0.132 & 0.973 & 4.559 & 1.8 & 0.990 & 18.03 & 3.13 & 0.937 \\
\hline 303 & 100 & 0.167 & 0.960 & 6.062 & 1.9 & 0.998 & 17.06 & 2.25 & 0.911 \\
\hline 308 & 100 & 0.217 & 0.956 & 8.093 & 2.2 & 0.994 & 15.01 & 1.37 & 0.895 \\
\hline
\end{tabular}

addition, $1246 \mathrm{~cm}^{-1}$, the amide III band, which is between 1320 and $1210 \mathrm{~cm}^{-1}$, is the $\mathrm{C}-\mathrm{O}$ stretch of the carboxylic acids. 1043 and $1077 \mathrm{~cm}^{-1}$ can be assigned to phosphate functional groups such as orthophosphate $\left(\mathrm{PO}_{4}{ }^{3-}\right)$, appearing as characteristic biosorption peaks at $1100-1030 \mathrm{~cm}^{-1} .^{28} 1654 \mathrm{~cm}^{-1}$ corresponds to the $\mathrm{N}-\mathrm{H}$ amine stretching band of the amino groups. ${ }^{16} 801$ and $885 \mathrm{~cm}^{-1}$, appearing as peaks at about $900-$ $800 \mathrm{~cm}^{-1}$, can be assigned to $\mathrm{C}-\mathrm{H}$ in aliphatic or aromatic bonds.

The disappearance of the significant bands at $801 \mathrm{~cm}^{-1}$ and $1149 \mathrm{~cm}^{-1}$ could indicate the elimination of some of the compound containing $\mathrm{C}-\mathrm{O}$ groups from the cell walls of the spores. The $1744 \mathrm{~cm}^{-1}$ peak located between 1700 and 1750 $\mathrm{cm}^{-1}$ appeared after biosorption. This is a carbonyl region, which means that some metal combined to carbonyl during biosorption. In addition, the fact that $1077 \mathrm{~cm}^{-1}$ changed to $1079 \mathrm{~cm}^{-1}$ means a reaction took place involving the phosphate functional groups, which is in accordance with the results of the EDX analysis (the change in P content). Also, the $1246 \mathrm{~cm}^{-1}$ peak shifting to $1258 \mathrm{~cm}^{-1}$ indicates changes in the secondary structure of proteins after denaturation or metal binding. ${ }^{23}$

The zeta potential represents the charge of the sample surface. As can be seen in Fig. 9, all of the samples were negatively charged gels and the sequence of the zeta potential absolute value was: fresh spores > spores dried at room temperature $>$ mutant spores under UV $>$ inactive spores. As the absolute value of the zeta potential decreased, the biosorption capacity of the samples also decreased. This phenomenon indicated that the biosorption process was related to electrostatic attraction.

\subsection{Kinetics analysis}

As can be seen in Fig. 10, the pseudo-second-order kinetic equation $\left(R^{2}=0.995\right)$ gave a slightly better fit than the intraparticle diffusion model $\left(R^{2}=0.92\right)$ and Lagergren's firstorder kinetic equation $\left(R^{2}=0.909\right)$.

Therefore, this biosorption was based on the pseudo-secondorder kinetic equation premise that the sorption rate was controlled by chemical sorption, ${ }^{25}$ and the results of the spore character analysis using FTIR and FETEM confirmed this data (Table 3).

Little physical sorption was involved in this process, because the data fit with the Lagergren's first-order kinetic equation as well $\left(R^{2}>0.9\right)$. In addition, intra-particle diffusion should be the rate-controlling step if the lines were to pass through the origin, which demonstrated that intra-particle diffusion was not the
Table 5 Thermodynamic parameters for the biosorption at different temperatures

\begin{tabular}{llllll}
\hline$\Delta G^{0}\left(\mathrm{~kJ} \mathrm{~mol}^{-1}\right)$ & & & & \\
\hline $293 \mathrm{~K}$ & $303 \mathrm{~K}$ & $313 \mathrm{~K}$ & $\begin{array}{l}\Delta H^{0}(\mathrm{~kJ} \\
\left.\mathrm{mol}^{-1}\right)\end{array}$ & $\begin{array}{l}\Delta S^{0}(\mathrm{~J} \\
\left.\mathrm{mol}^{-1} \mathrm{~K}^{-1}\right)\end{array}$ & $R^{2}$ \\
\hline-3.70 & -4.54 & -5.44 & 21.86 & 0.087 & 0.998
\end{tabular}

rate-controlling step. ${ }^{29}$ The dynamics of spore biosorption were in accordance with other kinds of fungus biosorbents. ${ }^{30}$

\subsection{Isotherm analysis}

The Freundlich model was slightly better than the Langmuir and Temkin models (Fig. 11a-c). The Freundlich model does not reveal the biosorption mechanisms, but it does generate information about the biosorption capacities of the system and predicts the behavior of the biosorption, which was a multilayer process ${ }^{31}$ and there was a heterogeneous distribution of active sites on the spores' surface ${ }^{32}$ (Table 4). Similar results were acquired by Jianlong, whose biosorbent was also Aspergillus niger. ${ }^{33}$ This phenomenon demonstrates that the component of Aspergillus niger spores did not affect the biosorption capacity, because the spores were derived from mycelium, therefore, the size and surface structure of the spores were the key factor in obtaining the high biosorption capacity.

\subsection{Thermodynamics analysis}

In order to understand the impact of temperature, spontaneity and feasibility of this adsorption system with spores, it is necessary to calculate and evaluate the various thermodynamic parameters of this process. ${ }^{14}$ As shown in Table 5, the negative values of $\Delta G^{0}$ indicate the spontaneous nature of the adsorption process. The positive value of $\Delta S^{0}$ shows the increasing randomness at the solid-solution interface during the adsorption process. The positive values of $\Delta H^{0}$ suggest the endothermic nature of the adsorption interaction. ${ }^{34}$ In addition, in Subbaiah's study, whose biosorbent was Trametes versicolor, a kind of fungus, similar thermodynamic regularity was found. ${ }^{34}$

\section{Conclusion}

(1) Spores of Aspergillus niger were used to biosorb cationic heavy metals. The maximum biosorption capacity of the spores was far higher than that of Aspergillus niger mycelium. In 
addition, the spores can reproduce in a large amount on agricultural waste.

(2) The spore biosorption mechanism included electrostatic attraction and ion exchange, which was supported by the results of EDX analysis and complexation involved in $\mathrm{C}=\mathrm{C}, \mathrm{C}-\mathrm{H}, \mathrm{C}-\mathrm{O}$ and $\mathrm{N}-\mathrm{H}$. The data fitted well with the pseudo-second-order kinetic equation and the Freundlich isotherm.

(3) FETEM showed that there was a combination of $\mathrm{Cu}$ and $\mathrm{O}$, and $\mathrm{CuO}$ was formed during the biosorption, as evidenced by the XPS results.

\section{Acknowledgements}

This study was financially supported by heavy metal wastewater treatment technology received from Heilongjiang Academy of Sciences (GC13C3042) and the heavy metal pollution emergency control of the National Environmental Protection Public Welfare Projects (201209048).

\section{References}

1 D. Sud, G. Mahajan and M. P. Kaur, Bioresour. Technol., 2008, 99, 6017-6027.

2 T. Akar and S. Tunali, Bioresour. Technol., 2006, 97, 17801787.

3 A. Kapoor and T. Viraraghavan, Bioresour. Technol., 1997, 61, 221-227.

4 M. Mukhopadhyay, S. B. Noronha and G. K. Suraishkumar, Bioresour. Technol., 2007, 98, 1781-1787.

5 N. L. Iskandar, N. A. I. M. Zainudin and S. G. Tan, J. Environ. Sci., 2011, 23, 824-830.

6 K. Tsekova, D. Todorova and S. Ganeva, Int. Biodeterior. Biodegrad., 2010, 64, 447-451.

7 Y. Khambhaty, K. Mody, S. Basha and B. Jha, Colloids Surf., A, 2008, 328, 40-43.

8 B.-E. Priegnitz, A. Wargenau, U. Brandt, M. Rohde, S. Dietrich, A. Kwade, R. Krull and A. Fleißner, Fungal Genet. Biol., 2012, 49, 30-38.

9 A. Wargenau, A. Fleißner, C. J. Bolten, M. Rohde, I. Kampen and A. Kwade, Res. Microbiol., 2011, 162, 1011-1017.

10 W. R. Bowen, R. W. Lovitt and C. J. Wright, Colloids Surf., A, 2000, 173, 205-210.

11 G. Guan, Z. Zhang, H. Ding, M. Li, D. Shi, M. Zhu and L. Xia, Biomass Bioenergy, 2015, 81, 224-233.

$12 \mathrm{H}$. Yu, J. Pang, T. Ai and L. Liu, J. Taiwan Inst. Chem. Eng., 2016, 62, 21-30.
13 A. S. Saini and J. S. Melo, Bioresour. Technol., 2013, 149, 155162.

14 M. O. Omorogie, J. O. Babalola, E. I. Unuabonah and J. R. Gong, Bioresour. Technol., 2012, 118, 576-579.

15 C. R. Teixeira Tarley, S. L. Costa Ferreira and M. A. Zezzi Arruda, Microchem. J., 2004, 77, 163-175.

16 S. Chen, Q. Yue, B. Gao, Q. Li and X. Xu, Chem. Eng. J., 2011, 168, 909-917.

17 J.-Y. Wang, H. Cui, C.-W. Cui and D.-F. Xing, Ecol. Eng., 2016, 95, 793-799.

18 M. Mukhopadhyay, S. B. Noronha and G. K. Suraishkumar, Chem. Eng. J., 2008, 144, 386-390.

19 A. Y. Dursun, Biochem. Eng. J., 2006, 28, 187-195.

20 İ. Sargın, G. Arslan and M. Kaya, Carbohydr. Polym., 2016, 138, 201-209.

21 M. Ajmal, A. Hussain Khan, S. Ahmad and A. Ahmad, Water Res., 1998, 32, 3085-3091.

22 Y. A. Yahaya, M. Mat Don and S. Bhatia, J. Hazard. Mater., 2009, 161, 189-195.

23 R. Drake, L. Shan and D. Rayson, Environ. Sci. Technol., 1996, 110-114.

24 C. Chen, D. Wen and J. Wang, Bioresour. Technol., 2014, 156, 380-383.

25 Y. Ding, D. Jing, H. Gong, L. Zhou and X. Yang, Bioresour. Technol., 2012, 114, 20-25.

26 F. Wang, X. Lu and X.-y. Li, J. Hazard. Mater., 2016, 308, 7583.

27 L. Ye, S. Wang, H. You, J. Yao and X. Kang, Chem. Eng. J., 2013, 226, 434-443.

28 T. Mathialagan and T. Viraraghavan, Bioresour. Technol., 2009, 100, 549-558.

29 I. Senturk, H. Buyukgungor and F. Geyikci, Desalin. Water Treat., 2015, 1-11, DOI: 10.1080/19443994.2015.1102088.

30 J. Huang, D. Liu, J. Lu, H. Wang, X. Wei and J. Liu, Colloids Surf., A, 2016, 492, 242-248.

31 G. M. Figueroa-Torres, M. T. Certucha-Barragán, E. AcedoFélix, O. Monge-Amaya, F. J. Almendariz-Tapia and L. A. Gasca-Estefanía, J. Taiwan Inst. Chem. Eng., 2016, 61, 241-246.

32 L. Yu and Y.-m. Luo, J. Environ. Chem. Eng., 2014, 2, 220-229.

33 W. Jianlong, Z. Xinmin, D. Decai and Z. Ding, J. Biotechnol., 2001, 87, 273-277.

34 M. V. Subbaiah, Y. Vijaya, A. S. Reddy, G. Yuvaraja and A. Krishnaiah, Desalination, 2011, 276, 310-316. 